\title{
O MUNICÍPIO NO BRASIL E SUA FUNÇÃO POLÍTICA (IV).
}

\author{
(Conclusão) .
}

\section{BRASIL BANDECCHI}

do Departamento de História da Faculdade de Filosofia, Letras e Ciências Humanas da Universidade de São Paulo e da Faculdade de Filosofia, Ciências e Letras de Franca.

\section{XI. - A LEI DE INTERPRETAÇÃO DO ATO ADICIONAL.}

Como vimos, o artigo 25 do Ato Adicional admitia que se houvesse dúvida sôbre a inteligência de algum de seus artigos, cabia a interpretação ao Poder Legislativo Geral. E essa interpretação passou logo a ser reclamada. Antes, porém, de ter a Assembléia Geral cogitado de elaborar a lei interpretativa, a Regência procurou por meio de Instruções, esclarecer os pontos duvidosos, não chegando, entretanto, a traçar a linha divisória entre a competência do Poder Central e as atribuições provinciais ou locais (190).

Cada vez mais se acentuava

\footnotetext{
"a necessidade de estabelecer uma regra de interpretação sôbre vários artigos do Ato Adicional",
}

pois que a Câmara dos Deputados sôbre êles havia levantado dúvidas e mesmo entendido sua aplicação de forma diversa, em mais de uma discussão. A urgência dessa interpretação se evidenciava com o exame que a Comissão competente havia feito de vários atos dos Legislativos Provinciais (191).

Com êste argumento convincente, a Comissão das Assembléias Provinciais da Câmara dos Deputados, inicia seu parecer sôbre a In-

(190). - Aurelino Leal, História Constitucional do Brasil, Rio de Janeiro, 1915, pág. 187. Vide, também, do mesmo autor, Do Ato Adicional à Maioridade, (História Constitucional e Política), Rio de Janeiro, 1915.

(191). - Parecer da Comissão das Assembleeias Provinciais da Câmara dos Deputados, de 10 de julho de 1837, sôbre a interpretação do Ato Adicional. 
terpretação do Ato Adicional, concluindo pelo Projeto do qual resultou a Lei de 12 de maio de 1840 .

Interpretado o Ato Adicional, ficava a Câmara dos Deputados aliviada de ir resolvendo separadamente os casos que the fôssem apresentados pelas Assembléias Provinciais.

Mesmo com o dispôsto nos artigos 10, 11 e 12 do Ato Adicional, que fixavam as atribuições legislativas das Assembléias Provinciais, não era possível afastar dúvidas que sempre afloravam.

Nenhum artigo da Lei se deve entender de modo que destrua outros da mesma Lei e os inutilize, proclama o parecer.

E sendo uma lei interpretativa outra não podia ser sua colocação. Mas o estudo da matéria não se apresentou fácil, o que levou a Comissão a estender o parecer por longas páginas mesmo tratando o assunto objetivamente.

As Assembléias Provinciais, dada a pouca clareza da lei, iam ao ponto de exorbitar das atribuições que thes foram outorgadas (192).

A Comissão depois de separar as competências, de dizer o que se devia entender por empregos gerais, provinciais e municipais (193), elucidado, então, o $\S 7 .^{\circ}$ do artigo 10 do Ato Adicional, quando êste autoriza as Assembléias Provinciais a legislar sôbre a criação e supressão dos empregados municipais e provinciais e estabelecimento dos seus ordenados, refere-se ao $\S 4^{\circ}$ do artigo 10 que também ocasionava dúvidas pelo que julgou a Comissão ser conveniente fixar sua inteligência:

"A Comissão entende que a palavra Municipal se refere a ambas as antecedentes - Policia e Economia - e que as seguintes - procedendo proposta das Câmaras - (grifos nossos), se referem a ambas aquelas.

(192). - Idem. "Não é de admirar - lê-se no parecer - que as Assembléias Legislativas Provinciais tenham exorbitado das atribuiçōes de que o Ato Adicional as revestira, porque têm natural tendência os Corpos deliberantes a transpôr as raias dos seus poderes. Era isto tanto mais natural em nosso País a respeito de Instituiçōes de recente data, mal entendidas em muitos lugares, e cuja inteligência não pode ainda fixar a diuturnidade dos tempos, a frequêencia das discussōes e a repetição dos casos".

(193). - "São empregados gerais os que dizem respeito à administração, arrecadação e contabilidade da Fazenda Nacional; à administração da Guerra e Marinha e dos Correios Gerais; os cargos de Presidente do Província, Bispo, Comandante Superior da Guarda Nacional, Membros da Relações e Tribunais Superiores, Empregados das Faculdades de Medicina, Cursos Jurídicos e Academias. Todos os mais que existem nas Províncias e Municípios são Provinciais ou Municipais. São, portanto Provinciais ou Municipais os empregos de Juiz de Direito, Chefes de Legião, Juizes Municipais, de Órfãos, de Paz, Promotor, de Pároco, Vereador etc.", idem. 
A Policia pois, segundo escritores abalisados, e segundo as Leis das Naçōes cultas, se divide em Polícia Geral e Municipal, e em Polícia Administrativa e Judiciária. A nossa Lei Orgânica das Câmaras Municipais capitulou muito exageradamente $\mathrm{cm}$ seu título $3^{\text {? }}$ os diversos objetos, que constituem entre nós a Polícia Municipal Administrativa.

A Comissão entende mais que a Policia de que fala o parágrafo em questão é essencialmente Municipal, e não esta. Nem é de supor que fôsse a intenção do Ato Adicional entregue a Polícia Judiciánia, que pode e deve ser uniforme no Império às Câmaras Municipais e às Assembléias Provinciais, e tornar independentes as Leis Policiais Judiciárias, da sanção dos Presidentes das Províncias. A Legislação Policial Judiciária constitui pois uma parte importantíssima da Legislação do Processo Criminal, cuja confecção sòmente pertence à Uniāo".

O projeto que a Comissão apresentou compreendia seis artigos (194), enquanto a Lei de 12 de maio de 1840 , que interpretou artigos da reforma da Constituição, ou seja, o Ato Adicional, tinha oito.

Tivemos, assim a Lei Interpretativa aprovada pela Assembléia Geral e sancionada pela Regência, cujo artigo 19 faz referência à palavra - Municipal - que consta do parágrafo $44^{\circ}$ do artigo 10 do Ato Adicional.

"A palavra Municipal - compreende ambas as anteriores polícia e economia - e a ambas estas se refere a cláusula final do

(194). - Projeto. Artigo $1^{\circ}$ - A palavra - Municipal - do artigo 10, \$ $4^{\circ}$ do Ato Adicional compreende ambas as outras anteriores - Polícia e Economia as quais dizem respeito às seguintes - procedendo proposta das Câmaras. - A palavra - Polícia - compreende sòmente a Policia Municipal Administrativa, e não a judiciária. Artigo $2^{\circ}-\mathrm{A}$ faculdade de criar e suprimir empregos Municipais e Provinciais, concedia às Assembléias Provinciais pelo \&. $7^{\circ}$ do artigo 10 do Ato Adicional, sòmente diz respeito ao número dos mesmos empregos, sem alteração de sua natureza e atribuiçōes quando forem estabelecidos por Leis Gerais relativas a objetos, sôbre os quais não podem legislar as referidas Assembléias. Artigo $3^{\circ}-$ O § 11 do mesmo artigo somente diz respeito aos Empregados provinciais criados por Leis Providenciais ou ainda mesmo Gerais relativas a objetos sôbre os quais podem legislar as Assembléias de Provincia. Artigo $4^{9}$ - A palavra - Magistrado - de que usa o $\$ 7^{\circ}$ do artigo 11 do mesmo Ato Adicional, não compreende aqueles que $0 \& 7^{\circ}$ do artigo 10 considera Gerais. Artigo $5^{\circ}-\mathrm{Na}$ decretação da suspensão e demissão dos Magistrados procedem as Assembléias Legislativas Provinciais como Tribunais de Justiça. Sòmente podem portanto impôr penas em virtude de queixas, por crime de responsabilidade a que elas estão impostas por Leis Criminais anteriores, observando a forma de Processo para tais casos anteriormente estabelecidas. Artigo $6^{9}-\mathrm{O}$ Decreto de suspensão ou demissão deverá conter: $1^{\circ}$, o relatório do fato; $2^{\circ}$, a citaçāo da Lei em que o Magistrado será incurso; $3^{\circ}$, uma sucinta exposição dos fundamentos capitais da decisão tomada. - Paço da Câmara dos Deputados, 10 de julho de 1837. 
mesmo artigo - precedendo propostas das Câmaras. A palavra polícia - compreende a polícia municipal e administrativa sòmente, e não a polícia judiciária".

O artigo $2{ }^{\circ}$ estatui que as Assembléias Legislativas, no que tange aos empregos estaduais e municipais, tinham poderes de criá-los e suprimí-los quanto ao número dos mesmos e não em lhes modificar as atribuições, quando êsses empregos fôssem estabelecidos por leis gerais e relativos a objetos sôbre os quais as Assembléias Provinciais não tinham competência para legislar. $\mathrm{O}$ artigo $3{ }^{\circ}$ teve por finalidade esclarecer que o parágrafo 11 do mesmo artigo 10 sòmente compreendia os empregos provinciais sobre os quais as Assembléias Legislativas Provinciais tinham competência para legislar, com isso excluiam os que se situavam na órbita da Assembléia Geral. O parágrafo 7 do artigo 11 referia-se a magistrados, e o artigo $4^{\circ}$ da mesma Lei excluiu os membros das Relações e dos Tribunais Superiores. Os artigos $5 .^{\circ}$ e $6 .^{\circ}$ tratam da suspensão e demissão de magistrados, casos em que as Assembléias Provinciais deviam proceder como Tribunal de Justiça. Mas essas penas só podiam ser aplicadas se motivadas por queixa e por crime de responsabilidade a que eram cominadas e já previstas em lei. Por fim o artigo $7^{\circ}$ trata da sanção negada pelo. Presidente da Província no caso de entender que o projeto ofendia a Constituição do Império e o $8 .^{\circ}$ que declara que as leis provinciais contrárias à interpretação dada, só se tinham por revogadas com ato expresso do Poder Legislativo Geral.

Pela interpretação dada às palavras e aos artigos, nota-se que a confusão reinante não era pequena. Por sua vez é de se destacar que a compreensão dada às palavras polícia e magistrado, fatalmente traria modificações no Código de Processo Criminal, assunto tratado no capítulo anterior.

Já dissemos que o eminente Tavares Bastos escreveu que a Lei de 12 de maio de 1840 amputou o Ato Adicional. Preferimos, nós, admitir que ela não foi interpretativa, porém, modificadora, com o que, acreditamos dar uma idéia mais clara do espírito que a orientou.

Agora, pelo que vimos na Lei de 1840 , conclui-se, tendo presente o Ato Adicional, que essa lei no pouco que falou do Município foi para reforçar o Ato no quanto êle feriu a autonomia local.

A Lei de Interpretação atingiu mais a Província, motivo que levou o autor das Cartas de um Solitário a voltar contra ela tôda a fôrça da sua crítica. Sua elaboração afastou-se do disposto no artigo 25 do Ato Adicional, não há que negar. E' meridiano. Indiscutível.

E' que a lei, conforme a situação, nem sempre se atem às estruturas legais existentes e afastando-se dos diplomas, atende a determi- 
nadas conveniências do momento, seguindo os interêsses do Estado e até dos legisladores e intérpretes.

Quando os autores da Constituição do Império, no capítulo dos Municípios, deixaram a matéria relativa ao exercício das funçồes municipais, formação de suas posturas políciais, aplicação das suas rendas e tôdas as suas particulareş e úteis atribuições para serem decretadas por uma lei regulamentar, tinham em mente, com certeza, a estabilidade da situação que esperavam se concretizasse e a possibilidade de se organizar a administração local sôbre bases seguras, consolidadas, resultado da consolidação da própria Monarquia. Mas do entre-choque das correntes em luta pelo poder, o terreno movediço sôbre o qual se assentaram o Primeiro Reinado e a Regência, o desejo insopitável de controlar a situação segurando, através dos Presidentes, as rédeas da Província, que, por sua vez tinha sob seu contrôle o $\mathrm{Mu}-$ nicípio, jamais dariam uma lei fortalecedora do govêrno local, núcleo eleitoral que se espalhava pelo arquipélago imenso do Brasil de então, e no tumulto de medidas justas e injustas, nulificaram a autonomia municipal.

A Lei de 12 de maio de 1840 foi, desta forma, mesmo sendo denominada também Interpretativa, uma consequiência lógica das incontroláveis marés dos interêsses em jogo e, notadamente, da nova estrutura político-administrativa que entâo se inaugurava com o Império recem-fundado

Basta dizer-se que ela é de 12 de maio, às vésperas, portanto, da culminância do movimento revolucionário, que fez de um menino de 15 anos, Imperador do Brasil, no dia 23 de julho de 1840 (195).

Incontestàvelmente, durante todo o Império, e para só falar neste período, a vida municipal brasileira procurou a autonomia perdida de forma insofismável a partir de 1828 . Até então, mesmo que por muitas vêzes fôsse arranhada aqui e ali, conforme os sucessos do momento, encontrava essa autonomia um pôrto onde se abrigar e fundamentos para se defender. A Constituição deixou caminho para que se desse ao Município o lugar político-administrativo que por direito

(195). - Afonso Arinos de Melo Franco prefere chamar ao movimento da maioridade de contra-revolução. E justifica seu modo de pensar: "Revolução política e parlamentar, é o título que traz em geral êste capítulo da nossa História. No entanto, colocando o assunto sob um certo ângulo de observação, parece que devemos repelir aquela denominação. Com efeito, analisada na sua significação profunda, a Maioridade nos aparecerá não como uma revolução, mas como uma contra-revolução. E isto mesmo, se considerarmos csta última expressão, no sentido que lhe atribuiu um grande pensador francês, ao dizer que a contra-revolução não é uma revolução contrária, mas o contrário de uma revolução". A Maioridade ou a Aurora do Segundo Reinado, obra organizada e revista por Brasil Bandccchi, editada pela Faculdade de Direito da Universidade de São Paulo, 1940, pág. 31. 
e por tradição lhe cabia. As leis posteriores, sob aspectos básicos, outra coisa não fizeram senão embaraçar e confundir competências.

Respigar os Anais da Câmara dos Deputados e do Senado a fim de trazer para o bojo desta tese, o protesto contra o estado de coisas reinante na área das nossas cogitações ou as tentativas de se dar rumo certo à falha legislação municipal, nos levaria a dilatadas páginas sôbre a matéria cuja prova não exige tanto.

A vida municipal preocupava govêrno e oposição, o que revela a importância do problema. Mas sempre que se trazia o problema para o plano das reformas, pelo menos os que eram da situação, não o enfrentavam como deviam.

De iniciativa governamental, temos dois trabalhos que merecem referência: o do Marquês de Olinda, Ministro do Império e Presidente do Conselho, em 1862 , e que não veiq siquer a ser discutido e outro do Visconde do Uruguai, Ministro do Império, em 1869, que chegou a receber parecer da Comissão da Câmara dos Deputados

O projeto de 1862 tentava reorganizar as Câmaras Municipais e procurava emancipá-las da tutela a que estavam sujeitas, mas em contra partida criava um administrador municipal escolhido pelo govêrno, investido de tantas atribuições que se transformaria no próprio Poder Municipal (196). O de 1869 era, também, arma de dois gumes, pois se de um lado procurava dar autonomia ao Município, de outro criava uma assembléia municipal, com membros não eletivos, à

\footnotetext{
"imitação dos Conselhos Gerais de França, sem necessidade que a isso obrigue" (197).
}

Faltava a ambos "um plano de reforma radical", não encaravam o problema com firmeza de princípios e sim com meias medidas que, em tais casos, nada resolvem. Esses projetos amoldavam-se ao regime do Ato Adicional; dai suas reformas não serem de maior profundidade no que tange a autonomia municipal, pois mantinham

"o vício orgânico da tutela e da centralização, mais ou menos disfarçadas por certos vislumbres de autonomia" (198).

(196). - Tavares Bastos, ob. Cit., pág. 153.

(197). - Idem, pág. 155.

(198). - Carneiro Maia, ob. cit., pág. 246. 
Um ano após a apresentação do projeto encaminhado à Câmara dos Deputados pelo Ministro do Império, Visconde do Uruguai, portanto, em 1870, veio a luz o Manifesto Republicano que põe em destaque a necessidade de alargar-se a esfera das municipalidades (199).

Assim chegamos à República. Pelos mesmos motivos que os fundadores do Império foram buscar nas corporações democráticas e tradicionais o embasamento popular que necessitavam, os arquitetos da República agiram de igual forma. Lúcidos republicanos como Olavo Bilac, José do Patrocínio, Anibal Falcão, Luís Murat, Campos da Paz e João Clapp, não foram no dia 15 de novembro à Câmara dos Deputados ou ao Senado que expontâneamente se dissolviam antes de o serem pelo govêrno que se instalava, mas à Câmara Municipal do Rio de Janeiro, onde, após acalmados alguns ânimos mais exaltados que desejavam a destruição dos retratos dos membros da Família Imperial, e reunidos vereadores e povo, foi lavrada e aprovada uma moção ao Govêrno Provisório em que encareciam a necessidade de ser sancionado o nôvo regime ali, na Câmara proclamado, ou seja o regime republicano (200).

Em São Paulo os republicanos agiram da mesma forma. Campos Sales, secretário interino da Comissão Permanente do Partido Republicano, no dia 16 de novembro enviou à Câmara um ofício em que informava aos Vereadores que haviam sido aclamados membros do Govêrno Provisório da Província os cidadãos Tenente-Coronel Joaquim de Sousa Mursa e os drs. Prudente de Morais Barros e Rangel Pestana e que por ocasião da aclamação do Triunvirato o povo da Capital havia resolvido reunir-se às 11 horas daquele dia no Paço da Câmara Municipal, para proclamar a República em São Paulo, pelo que o Govêrno Provisório contava com a colaboração da edilidade (201).

E assim, às 11 horas do dia 16 de novembro de 1889 , no Paço Municipal, foi proclama a República em São Paulo e em seguida empossados os membros do Triunvirato, não tendo comparecido o cida-

(199). - In A República, número de 3 de dezembro de 1870. Foi êste Manifesto reproduzido na íntegra n'O Estado de São Paulo, de 3 de dezembro de 1970.

(200). - Veja-se Galeria Histórica da Revolução Brasileira, de autoria de Urias A. da Silveira, Rio de Janeiro, 1890, págs. 179-180. Obra raríssima que publica importante documentação sôbre a proclamação da República.

(201). - Manuscrito do Arquivo Municipal de São Paulo, Papeis avulsos. 
dão Joaquim de Sousa Mursa por encontrar-se ausente (202). Um dos primeiros atos do Govêrno Provisório de São Paulo constituiu na adesão do Estado de São Paulo à República dos Estados Unidos do Brasil (203) .

O Triunvirato que exerceu suas funções de 16 de novembro a 14 de dezembro de 1889 teve como missão exclusivamente manter a ordem e fazer respeitar a República (204).

Prudente de Morais, nomeado governador do Estado de São Paulo (205) em 8 de dezembro, no dia 11 oficiou à Câmara Municipal, soliciando fôssem marcados dia e hora para que tomasse posse do cargo (206). E o Presidente da Câmara Municipal, Major Domingos Sertório, no mesmo papel designou para a pose o dia 16 de dezembro, ao meio dia (207).

Cumprida a missão política da Câmara, o Govêrno Provisório, da República, pelo Decreto no 50 de 7 de dezembro de 1889, dissolveu a Câmara do Rio de Janeiro e em seu lugar criou o Conselho de Intendência Municipal. A mesma sorte tiveram as demais, sendo que o Conselho de Intendência de São Paulo foi criado no dia 15 de janeiro de 1890 (208).

(202) . - A Ata de Posse dos membros do Govêrno Provisório foi lavrada em um livro especial sendo que nesse livro nada mais se registiou. Assinam-na, além dos vereadores, dois dos membros do Triunvirato e todos os cidadãos presentes ao ato. Este livro de atas encontra-se no Arquivo Municipal de São Paulo.

(203). - Eugênio Egas, Galeria dos Presidente de São Paulo. - Periodo Republicano (1889-1920), Publicação Oficial do Estado de São Paulo, comemorativa do $1^{\circ}$ Centenário da Independência do Brasil, vol. II, São Paulo, 1927, pág. 12.

(204). - Idem, ibidem.

(205). - Com a Proclamação da República as Províncias passaram a denominar-se Estados.

(206). - No Brasil Colonial, os governadores quase sempre tomavam posse perante as Câmaras municipais. No Império, de acôrdo com o artigo 53 da Lei de $1^{\circ}$ de outubro de 1828, os presidentes das Províncias o faziam nas Câmaras Municipais das Capitais, com lavratura do respectivo têrmo, assinado pelo empossado e pelos vereadores. Criadas as Assembléias Legislativas Provinciais, (artigo $1^{\text {Q }}$ do Ato Adicional), passaram os Presidentes a tomar posse perante elas, só fazendo perante a Câmara Municipal da Capital quando a Assembléia Provincial não estivesse reunida (artigo 10 da Lei de 3 de outubro de 1834).

(207). - Manuscrito do Arquivo Municipal de São Paulo, Papéis avulsos.

(208). - Decreto $\mathrm{n}^{9} 13$, de 15 de janeiro de 1890, do govêrno de São Paulo, in Decretos e Resoluções do Governador, ano de 1890, págs. 20 e segts. Num dos seus considerandos está ressaltada a "necessidade de garantir os inestimáveis benefícios da instituição da autonomia municipal, pela prevenção e repressão de quaisquer anormalidades". Diz seu artigo $1^{\circ}$ - "Até a definitiva constituição dos Esta- 
Prudente de Morais nomeado governador de São Paulo no infcio do nôvo regime, sucedendo ao Triunvirato que governou o Estado nos primeiros dias republicanos, assinou o Decreto $n^{0} 13$, de 15 de janeiro de 1890, sôbre a administração municipal e em cujos considerandos se refere à tutela administrativa exercida durante mais de meio século (209) sôbre os Municípios, e que produzira o entorpecimento e a penúria de sua vida econômica e a urgente necessidade de emancipá-los, confiando-lhes a faculdade de proverem aos seus próprios negócios, segurdo a índole do regime nascente (210).

Adotara o Brasil, como forma de govêrno, sob o regime representativo a República Federativa (211).

Em consonância com o espírito federalista, o artigo 68 da Lei Magna da República, consagrava que os Estados organizar-se-iam de forma a que ficasse assegurada a autonomia dos Municípios em tudo quanto respeitasse ao seu peculiar interêsse. Deixava, assim, de existir uma lei única para todo o Brasil, sôbre as municipalidades, devendo, dai por diante, cada Estado da Federação, ao organizar-se respeitar a autonomia proclamada no citado artigo. Os Estados passaram a decretar as próprias leis orgânicas municipais. Mesmo com a República Federativa, o problema municipal não teve a so'ução desejada, e daí a luta constante dos municipalistas aspirando maior autonomia política e financeira, que é tema principal dos Congressos de Municípios, o que repercute nas Assembléias Estaduais, na Câmara dos Deputados Federais e no Senado da República.

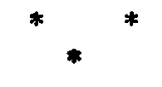

dos Unidos do Brasil, ou antrs, se assim convier, o poder ou govêrno dos municípios do Estado de São Paulo será exercido por conselhos de intendência municipal nomeados pelo Governador". E $0 \S 1^{\circ}$ do artigo $2^{\circ}$ - "Os Conselhos de Intendência delibe: arão sôbre todos os assuntos de competência das câmaras municipais, segundo a lci de $1^{\circ}$ de outubro de 1828 e mais leis em vigor". E o artigo $7^{\circ}$ - "O Governador do Estado reserva-se o direito de cassar ou anular as deliberações ou posturas municipais, que forem contrárias às leis do Estado ou da Nação, ou prejudiciais ao interêsse do município, do Estado ou da Nação". Este estado de coisas durou até a promulgação da Constituiçăo de 1891, cujo artigo 68 rczava - "Os Estados organizar-se-ão de forma que fique assegurada a autonomia dos municipios em tudo quanto respeite ao seu peculiar interêsse".

(209). - "Durante mais de meio século..." A contar de 1890 atinge exatamente a época em que foram votados o Ato Adicional e a Lei de Interpretação de 1840.

(210). - Decreto e Resoluções do Govêrno, ano de 1890, pág. 20 e segts.

(211). - Artigo $1^{\circ}$ da Constituição de 1891. O Decreto $n^{\circ} 1$, de $1 .{ }_{n}$ de novembro de 1889, do Govêrno Provisói io dispunha: "Fica proclamada provisòriamente e decreta como forma de govêrno da Nação Brasileira - A República Fcderativa". 


\section{CONSIDERAÇÕES FINAIS.}

No período co'onial, gozavam as Câmaras Municipais de autonomia no que fôsse de seu peculiar interêsse, como órgão administrativo, e como órgão político participavam dos negócios do Estado, davam posse a governadores e altos funcionários, praticavam inúmeros atos de natureza política, chegando mesmo a exorbitar de suas atribuições. Eram legítimas representantes do povo, não se justificando a afirmação de que não se revestiam de caráter democrático, conforme está demonstrado.

As poucas leis que citamos relativas ao Município no Brasil colonial, com exceção dos forais que eram a constituição de cada um, porém iguais ou com mínimas diferenças; é indício de que gozavam os Concelhos de autonomia, os quais faziam suas posturas de acôrdo com os interêsses e urgências, usos e costumes locais.

A Constituição do Império, livre de qualquer influência direta, traçou em três artigos a base sôbre a qual devia se assentar o Regimento das Câmaras Municipais (Lei de 1828), que seria a estrutura legal da vida política e administrativa das Cidades e das Vilas. Acontece que a Lei de $1^{\circ}$ de outubro de 1828 afastou-se da Lei Maior, e por isso tornou-se um diploma manco.

No Império, em concorrência às funções político-administrativas das Câmaras Municipais, foram criados os Conselhos Provinciais (depois transformadas pelo Ato Adicional em Assembléias Legislativas Provinciais), a Câmara dos Deputados e o Senado, causa principal da nulificação dos Concelhos. Na Colônia e nos primeiros anos de Império, eram as Câmaras Municipais os únicos órgãos de representação popular, dai a soma imensa dos seus poderes. Com a nova estrutura, teve o povo outros órgãos de representação, órgãos êsses de mais fácil contrôle político. E é através das Assembléias Provinciais, sucessoras dos Conselhos Gerais, que o Poder Central passou a comandar a política nacional, sacrificando, indevidamente, a autonomia dos Municípios.

Mas êste sacrifício indevido das Câmaras foi constante preocupação dos estadistas do Império e da República. A autonomia munici- 
pal é permanente aspiração dos povos, porque ela tem raizes na nossa formação histórica e configuração geográfica. A República tem procurado dar ao Município o lugar que por tradição e direito lhe cabe no amplo cenário da vida política nacional.

Por tradição e por direito!

As Câmaras Municipais tiveram papel decisivo nos grandes momentos históricos durante o Brasil-Colônia, como depois, na Campanha do "Fico", na Aclamação de D. Pedro, primeiro Imperador e Defensor perpétuo do Brasil; no momento de promulgar a Constituição do Império, em que as Câmaras foram chamadas a opinar sôbre o Projeto, dando, desta forma, direta ou indiretamente, sua anuência; na proclamação da República, quando foram disolvidos o Senado, a Câmara dos Deputados e as Assembléias Provinciais e sòmente as Câmaras Municipais permaneceram, foi na do Rio de Janeiro que o povo se reuniu para proclamar o nôvo regime; foi, ainda, na Câmara de S. Paulo que os paulistas se reuniram para proclamar a República para, depois, aderir ao Movimento vitorioso na Capital do país. Também na Câmara Municipal de São Paulo, tomaram posse a Junta Governativa e o primeiro Presidente republicano.

Falharam, portanto, os legisladores de 1828,1834 e 1840 . Só não falharam a tradição e a consciência histórica, porque sempre presentes nas lutas pela autonomia municipal. 


\section{FONTES E BIBLIOGRAFIA.}

\section{MANUSCRITOS.}

Papéis avulsos existentes no Arquivo Municipal de São Paulo referentes à Proclamação da República.

- Ofício do Dr. Manuel Ferraz de Campos Salles, então secretário interino da Comissão Permanente do Partido Republicano de São Paulo, a Câmara da Capital comunicando no dia 16 de novembro de 1889 a escôlha dos membros do Govêrno Provisório e solicitando que a mesma se reunisse com o povo, ainda naquele dia, às 11 horas, para a proclamação da República em São Paulo e posse dos cidadãos que governariam São Paulo até a nomeação do primeiro governador republicano do Estado.

- Ata da proclamaçāo da República em São Paulo e posse dos membros do Govêrno Provisório, lavrada em livro especial que jamais foi utilizado para a lavratura de têrmo de qualquer outro ato.

- Ofício de 11 de dezembro de 1889 de Prudente de Morais, comunicando ao Presidente da Câmara Municipal de São Paulo ter sido, por ato daquele mês assinado pelo Govêrno Provisório da República, nomeado Governador de São Paulo e solicitando convocação de uma sessão extraordinária daquele órgão de representação popular para, perante êle, ser empossado no cargo.

\section{IMPRESSOS.}

Anais do Parlamento Brasileiro. Assembleia Constituinte (1823) 6 tomos. $1^{9}$ Tomo, Tipografia de Hipolito José \& Cia., Rio de Janeiro, 1876; $2^{\circ}$ Tomo, Tipografia Parlamentar (*), Rio de Janeiro, $1877 ; 3^{\circ}$ Tomo, Tipografia Hipolito José Pinto, Rio de Janeiro, 1878; $4^{\circ}$ Tomo, idem, 1879; $5^{\circ}$ Tomo, idem, 1880 e $6^{\circ}$ Tomo, Tipografia da Viúva Pinto \& Filho, Rio de Janeiro, 1884.

(*). - Esta tipografia era de propriedade de Hipolito José Pinto, que desfez sociedade que tinha e já em 1878 passou a denominar-se novamente Hipolito José Pinto, sem sócio, porém. Por seu falecimento a tipografia passou a denominar-se Viúva Pinto \& Filho. 
Anais do Parlamento Brasileiro. Camara dos Senhores Deputados (1826-1888), Tipografia Imperial e Constitucional, de J. Villeneuve \& Cia. Rio de Janeiro.

Anais do Senado do Império. Tipografic Mercantil, Rio de Janeiro.

Anais da Assembleias Legislativa da Provincia de Säo Paulo (1835-1887), Sociedade Impressora Paulista. São Paulo, 1887-1929.

Anais do Rio de Janeiro, vide LISBOA, Baltazar da Silva, in Bibliografia.

Anais Pernambucanos, vide COSTA, Francisco Augusto Pereira da, in Bibliografia.

Atas da Câmara (Salvador, Bahia), 6 volumes. De 1625 a 1700 . Editado pela Prefeitura da Cidade do Salvador. $1^{\circ}$ e $2^{\circ}$ vols. s/d.; $3 .^{\circ}$ e $4 .^{\circ}, 1949$; $5^{\circ}, 1950$ e $6^{\circ}, \mathrm{s} / \mathrm{d}$.

Atas da Câmara da Vila de São Paulo (1562-1719); vols. de 1 a 8, impressos os 6 primeiros pela Duprat \& Cia., em 1914-1915. Os vols 7 e 8, pela própria Prefeitura de São Paulo em 1915.

Atas da Câmara Municipal de São Paulo (*) (1720-1829), vols. 9 a 24, Arquivo Municipal de São Paulo, impressos pela Prefeitura, 1916-1922.

Atas das Sessões da Câmara Municipal de São Paulo (Conselho de Intendência de São Paulo), 1889-1890, Editôra Espíndola \& Cia. São Paulo. 1905-1906.

Carta do Ouvidor Geral Pêro Borges ao Rei D. João II, datada de 7 de fevereiro de 1550, cujo original se encontra no Arquivo Nacional da Tôrre do Tombo (Cf. Serafim Leite, Cartas dos Primeiros Jesuitas do Brasil, vol. I, São Paulo, 1954). Transcrita por Waldemar Ferreira na sua História do Direito, vol. II, Rio de Janeiro-São Paulo, 1952 e por Varnhagen em sua História Geral do Brasil, Tomo I, 6a. ediçāo. Sāo Paulo, 1956.

Cartas do Senado (Câmara do Salvador), 1673-1684, $2^{\circ}$ vol. Documentos Históricos do Arquivo Municipal da Prefeitura do Salvador. Bahia, 1952 (?).

Coleçāo das Decisões do Govêrno do Império do Brasil (1828 a 1889), Tipografia Nacional - Imprensa Nacional, Rio de Janeiro, 1877-1889.

Documentos Históricos (1675-1709), vol. XI da Série e IX dos Documentos da Biblioteca Nacional. Augusto Pôrto \& Cia., Rio de Janeiro, 1929.

Fala do Trono lida por D. Pedro I em 3 de maio de 1823. Anais do Parlamento Brasileiro. Assembléia Constituinte, 1823. Tomo I, Tipografia Hipolito José Pinto \& Cia. Rio de Janeiro, 1876.

Fala do Trono, Regência 1838, Anais da Câmara dos Deputados, Tomo I, Tipografia Imperial, Rio de Janeiro, 1874.

(*). - A partir do ano de 1720 passam a ter êsse título e não mais Atas da Câmara da Vila de São Paulo, pois desde 1711 São Paulo já gozava da dignidade de Cidade. 
Manifesto Republicano de 1870 publicado no $\mathrm{n}^{2} 1$ do jornal $A$ República; Rio de Janciro, 3 de dezembro de 1870 , havendo um exemplar na Bibliotéca do Instituto Histórico e Geográfico de São Paulo. Reproduzido na integra ultimamente, n'O Estado de São Paulo, de 3 de dezembro de 1970 e na Revista de História, Vol. XLI, $n^{\circ} 84$, nesta com Introdução e Comentários de Reynaldo Carneiro Pessoa.

Parecer da Comissão das Assembléias Provinciais da Câmara dos Deputados, de 10 de julho de 1837, sôbre a Interpretaçāo do Ato Adicional.

Projeto de Constituiçāo para o Império do Brasil, Anais do Parlamento Brasileiro, Assembléia Constituinte, 1823, Tomo V.

Registro da Patente do Sr. Antônio da Silva Caldeira Pimentel, de governador da Capitania de São Paulo, in Documentos Interessantes para a História de São Paulo, vol. XXXVIII (1721-1738). Arquivo do Estado de São Paulo, 1902.

Idem, do Conde de Sarzedas.

Registro Geral da Câmara Municipal de São Paulo (1820-1822), vol. XVI Arquivo Municipal de São Paulo, São Paulo, 1922.

Tombo das Cartas das Sesmarias do Rio de Janeiro (1594-1595), Ministério da Justiça, Arquivo Nacional, Rio de Janeiro, 1967.

\section{LEGISLAÇÃO BÁSICA.}

Alvará de 5 de Novembro de 1604, que determina que os procuradores que as Câmaras mandassem à Côrte não tratassem de nenhum negócio em seu próprio nome ou de terceiros, devendo dedicar-se sòmente aos negócios dos povos de que eram mandatários. (Leis Extravagantes, vol. I, págs. 30-32, Coimbra, 1819).

Alvard de 12 de Novembro de 1611, que introduz modificaçōes no Livro I, Título 67, das O:denações ilipinas, no que tange às eleiçōes municipais. (Idem, pág. 159).

Ato Adicional à Constituição do Império do Brasil (Lei de 12 de Agôsto de 1834).

Carta de Lei de 12 de Outubro de 18.32, que autorizou a Reforma da Constituição do Império do Brasil, conforme estabelecia o artigo 174 deste Magno Diploma.

Código do Processo Criminal de Primeira Instancia do Império do Brasil, organizado e anotado pelo Conselheiro Vicente Alves de Paula Pessoa, editado no Rio de Janeiro em 1882 .

Constituiçäo Esponhola de 1812 reproduzida integralmente na parte História das Constituiçöes da História do Brasil-Reino e Brasil-Império de A. J. Melo Morais, Rio de Janeiro, 1871. 
Constituição Portuguêsa de 1820, idem.

Constituição Politica do Império do Brasil (Carta de Lei de 25 de Março de 1824.

Decreto de 13 de Novembro de 1823, que criou o Conselho de Estado, o qual foi extinto em 25 de março de 1824, quando foi promulgada a Constituição do Império.

Decreto $n^{o} 13$ de 15 de janeiro de 1800 , do govêrno de São Paulo, sôbre administração Municipal.

Lei de 20 de outubro de 1823, que manda vigorar provisòriamente no Império do Brasil as Ordenações, Leis e Decretos promulgados pelos Reis de Portugal até 25 de abril de $1821 \mathrm{e}$, depois dessa época aos do Regente D. Pedro e as das Côrtcs Portuguêsas, relacionadas em uma tabela.

Lei de $1^{\circ}$ de outubro de 1828 (Regimento das Câmaras Municipais).

Lei de 12 de outubro de 1832 que deu origem ao Ato Adicional.

Lei de 3 de outubro de 1834, sôbre a autoridade dos Presidentes das Provincias.

Lei de Interpretação do Ato Adicional, de 12 de maio de 1840.

Lei de 3 de dezembro de 1841, que reforma o Código do Processo Criminal de 1832. Ordenaçōes do Reino:

1). - Afonsinas (1446-1521).

2). - Manuelinas (1521-1603).

3). - Filipinas (1603 - derrogadas com leis que foram sendo promulgadas no Brasil após a Independência, vigiram, em mínima parte, no Brasil, até 1917, ano em que entrou em vigor o Código Civil).

Regimento dado ao Governador-Geral Tomé de Sousa, em 17 de dezembro de 1548. Reproduzido na integra na História da Colonizaçāo Portuguêsa do Brasil, vol. III.

Regimento dado ao Governador Roque Barreto (1677). Reproduzido por J. I. Martins Junior in Históric do Direito Nacional.

\section{BIBLIOGRAFIA.}

ABREU (J. Capistrano de). - Capitulos de História Colonial, Ediçāo da Sociedade Capistrano de Abreu, Rio de Janeiro, 1928.

ACCIOLI (I) e AMARAL (Braz do). - Vide SILVA (Ignácio Accioli de Cerqueira e).

AgUIAR (Pinto de). - A abertura dos Portos do Brasil, Livraria Progresso Editora, Bahia, 1960. 
ALMEIDA (Aluísio de). - A Revoluçăo Liberal de 1842, Livraria José Olympio Editôra, Rio de Janeiro, 1944.

ALMEIDA (Cândido Mendes de). - Código Filipino ou as Ordenaçōes e Leis do Reino de Portugal - $14^{\mathfrak{a}}$ edição, Tipografia do Instituto Filomático, Rio de Janeiro, 1870.

ALMEIDA (Fortunato de). - História de Portugal, Coimbra, 1929.

AMARAL (Braz do). - Resenha Histórica da Bahia, Tipografia Naval - Bahia 1941.

AMORIM (Deolindo). - Da evolução do Municipio no Brasil in Revista do Instituto Histórico e Geográfico Brasilciro, IV Congresso de História Nacional, Anais. $9^{\circ}$ vol., 21 de abril de 1949. Departamento de Imprensa Nacional, Rio de Janeiro, 1951.

ARMITAGE (João). - História do Brasil (1808-1831), $2^{\text {a }}$ edição brasileira anotada por Eugênio Egas, São Paulo, 1914.

ARRIAGA (José d'). - História da Revolução Portuguêsa de 1820 (4 volumes), Porto, 1886-1889.

AVELAR (Hélio de Alcantara) e TAUNAY (Alfredo d'Escragnole). - História Administrativa do Brasil, Vol. I, 1956. TAPAJOS (Vicente). - Idem, Vol. II, 1956. GUEDES (João Alfredo Libânio) e RIBEIRO (Joaquim). -Idem, Vol. III, 1957. GUEDES (João Alfredo Libânio). - Vol. IV. 1962. Edição do D.A.S.P. Serviço de Documentação, Rio de Janeiro.

AZEVEDO (Aroldo de). - Embriōes de Cidades Brasileiras, Separata do Boletim Paulista de Geografia, $n^{\circ}$ 25, março de 1957, São Paulo, 1957.

AZEVEDO (Aroldo de). - Arraiais e Curutelas, Separata do Boletim Paulista de Geografia n 27, outubro de 1957, São Paulo, 1957.

AZEVEDO (Aroldo de). - Vilas e Cidades do Brasil Colonial, (Ensaio de geografia urbana retrospectiva) in Boletim, Universidade de São Paulo, $\mathrm{n}^{\circ} 208$, São Paulo, 1956.

AZEVEDO (Julião Soares de). - Condiçôes econômicas da Revolução de 1820, Lisboa, 1944.

BANDECCHI (Brasil). - Elementos de História do Direito Brasileiro. Separata da Revista do Arquivo Municipal, vol. CLXXIX, Prefeitura de São Paulo, 1969.

BARRETO (Paulo Thedin). - Casas de Câmara e Cadeia, in Revista do Património Histórico Nacional, $\mathrm{n}^{\circ}$ 11, Rio de Janeiro, 1947.

BARRETo (Plínio). - A Cultura Juridica no Brasil, Biblioteca d" "O Estado de São Paulo" n 2, São Paulo, 1922. 
BARRETO (Tobias). - Um discurso em mangas de camisa in Estudos de Sociologia, Instituto Nacional do Livro, MEC., Rio de Janeiro, 1962.

BASTOS (Tavares). $-A$ provincia $-2^{\text {a }}$ ediçāo, Companhia Editôra Nacional, São Paulo, 1937.

BEVILAQUA (Clóvis). - Direito das Coisas, $1^{\circ}$ vol., Livraria Freitas Bastos, Rio de Janeiro, 1941.

BUENO (José Antônio Pimenta). - Direito Público Brasileiro e análise da Constituiçâo do Império, Tipografia Imp. e Const. de J. Villeneuve, Rio de Janeiro, 1857.

BUENO (José Antônio Pimenta). - Apontamentos sôbre o Processo Criminal Brasileiro - $2^{\text {a }}$ ed. Emprêsa Nacional do Diário, Rio de Janeiro, 1857.

CABRAL (Veiga). - História do Brasil (Curso Superior), 16 a edição, Rio de Janeiro, 1949.

CALIXTO (Benedito). - Capitanias Paulistas, Casa Duprat e Casa Mayença (reunidas), São Paulo, 1927.

CALIXTO (Benedito). - Capitania de Itanhaem, in vol. $\mathrm{XX}$ da Revista do Instituto Histórico e Geográfico de Säo Paulo, São Paulo.

CALMON (Pedro). - Curso de Direito Constitucional Brasileiro, Livraria Freitas Bastos, Rio de Janeiro, 1947.

- História do Brasil (7 volumes) - $2^{\natural}$ Ed., Livraria José Olympio, Rio de Janeiro, 1963.

CALOGERAS (J. Pandiá). - Formaçāo Histórica do Brasil - $6^{7}$ ediçāo, Companhia Editôra Nacional, São Paulo, 1966.

CÂMARA (José). - Subsidios para a História de Direito Pátrio. I vol. 1500-1769; Livraria São José, Rio de Janeiro, 1957; II vol. (ou tomo) - 1769-1822, Livraria Brasiliana Editôra, Rio de Janeiro, 1964; III vol. (ou tomo) 1822-1889, idem, 1966; IV vol. (ou tomo) - 1889-1930, idem, 1967.

CAMÓES (Luís de). - Os Lusiadas. Frefácio de Afrânio Peixoto, W. M. Jackson Inc. Editôres, Rio de Janeiro, São Paulo, Pôrto Alegre, 1948.

CAMPOS (Silva). - Crônica de Capitania de São Jorge dos Iheus, Imprensa Vitória, Bahia, 1947.

'CARNEIRo (Edson). - A Cidade do Salvador, Ed. da Organização Simões, Rio de Janeiro, 1954.

CARVAlho (Joaquim de). - A obra legislativa das Côrtes, in História de Portugal, Volume VII, Barcelos, 1935.

CARVAlHo (Orlando M.). - Problemas Fundamentais do Municipio, Companhia Editôra Nacional, São Paulo, 1937. 
CARVAlHo (Orlando M.): - Politica do Municipio. (Ensaio histórico), Livraria Agir Editôra, Rio de Janeiro, 1946.

CAVALCANTI (Themístocles Brandão). - Teoria do Estado, Editor Borsoi, Rio de Janeiro, 1958.

- Instituiçōes de Direito Administrativo Brasileiro (2 vol.), $2^{\text {a }}$ edição, Livraria Editôra Freitas Bastos, Rio de Janeiro, 1938.

CORREA FILHo (Virgílio). - História de Mato Grosso, Instituto Nacional do Livro, MEC, Rio de Janeiro, 1969.

COSTA (Francisco Augusto Pereira da). - Anais Pernambucanos (1493-1739) (5 volumes), Arquivo Público Estadual, Recife, 1951.

CRUZ (Guilherme Braga da). - História do Direito Português. Publicação devidamente autorizada, das liçoos proferidas ao $1^{9}$ ano Jurídico 55-56 pelo Exmo. Sr. Prof. Doutor Braga da Cruz, coligidas por A. Barbosa de Melo, Coimbra, 1955.

DELORENZO NETO (Antônio). - Problemas fundamentais na organização dos Municípios e Reforma da Lei Orgânica in Estudos Municipais, $\mathrm{n}^{\circ}$ 1, São Paulo, 1958.

DEUS (Frei Gaspar da Madre de). - Memórias para a História da Capitania de São Vicente, Weiszflog Irmãos, São Paulo - Rio de Janeiro, 1920.

DIAS (Manuel Nunes). - O Descobrimento do Brasil, Editôra Pioneira, São Paulo, 1967.

DRUMMOND (Vicior). - Rio de Janeiro capital do Brasil (1763-1822), 1. ${ }^{\circ}$ vol. Secretaria da Educação e Cultura do Estado da Guanabara, 1965.

EÇA (V. de Almeida de). - Abertura dos Portos do Brasil, I.isboa, 1908.

—_ Normas econômicas das Colônias Portuguêsa até 1808, Coimbra, 1921.

EGAS (Eugênio). - Os Municipios Paulistas (2 voumes), (Publicação Oficial São Paulo), Secção de Obras d' "O Estado de São Paulo", São Paulo, 1925.

- Galeria dos Presidentes de São Paulo - Periodo Repúblicano (1889-1920). Publicação Oficial do Estado de São Paulo, Vol. II., São Paulo, 1927.

ELLIS JÚNIOR (Alfredo). - Capitulos de História Social de São Paulo, Companhia Editôra Nacional, São Paulo, 1944.

FERREIRA (Waldemar). - o Direito Público Colonial do Estado do Brasil sob o signo pombalino, Editôra Nacional de Direito Ltda., Rio de Janeiro, 1960.

- História do Dircito Brasileiro (4 volumes), $1^{\circ}$ vol., Saraiva, São Paulo, $1962 ., 2^{\circ}$ vol., Freitas Bastos, Rio de Janeiro-São Paulo, 1952., $3^{\circ}$ vol., Max Limonad, Sāo Paulo, 1955., $4^{\circ}$ vol., Idem, 1956.

FLEIUSS (Max). - História Administrativa do Brasil, $2^{\circ}$ edição, Cia. Melhoramentos de São Paulo, São Paulo s/d. 
FONSECA (Roberto Piragibe). - Breviário de Princípiologia Juridica, Distribuidora Récord Editôra, Rio de Janeiro, 1958.

FORJAZ (Djalma). - O Senador Vergueiro sua vida e sua epoca (1778-1859), $1^{\circ}$ volume. Oficina do "Diário Oficial", Sāo Paulo, 1924.

FRANCO (Afonso Arinos de Mello). - El constitucionalismo brasileño em la primera mitad del siglo $X I X$ in El Constitucionalismo a mediados del siglo $X I X$ (2 volumes) Publicaciones de la Faculdad de Derecho de la Universidad Nacional, Autónoma de México, México, D. F., 1957.

FRANCO (Afonso Arinos de Mello). - A maioridade ou a aurora do Segundo Reinado, Edição da Faculdade de Direito da Universidade de São Paulo, 1940.

FREIRE (Hilário) e VIANNA (Oliveira). - A formaçāo das cidades, in Revista do Brasil, vol. XXV, novembro de 1923, Editada em São Paulo por Monteiro Lobato \& Cia., 1923.

GIRÃO (Raimundo). - Geografia estética de Fortaleza, Imprensa da Universidade do Ceará, Ceará, 1959.

HANDELMANN (Henrique). - História do Brasil. Tradução brasileira por Lúcia Furquim Lalmeyer e revista, por Bertoldo Klinger, Edição do Instituto Histórico e Geográfico Brasileiro, Rio de Janeiro, 1931.

HERCULANO (Alexandre). - Oprisculos, Tomo VI, Apontamento para a História dos Bens da Coroa e dos Forais - 4a Edição, Livraria Bertrand, Lisboa, Livraria Francisco Alves, Rio de Janeiro-São Paulo-Belo Horizonte s/d.

- História de Portugal (8 volumes), Livraria Aillaud \& Bertrande, Paris-Lisboa, Livraria Francisco Alves, Rio de Janeiro, São Paulo, Belo Horizonte.

HOLANDA (Sérgio Buarque de). - História Geral do Brasil, (sob a direção de). Vols. I e II, 1960; Vol. III, 1962; Vol. IV, 1964. Difusão Europẻia do Livro, São Paulo.

- Raizes do Brasil - Livraria José Olympio, Rio de Janeiro, 1936.

- Caminhos e Fronteiras, Livraria José Olympio, Rio de Janeiro, 1957.

JAVARt (Barāo de). - Organizaçōes e Programas Ministeriais, (Regime Parlamentar do Império), Ministério da Justiça e Negócios Interiores, Rio de Janeiro, 1962.

LAXE (Joāo Batista Cortines). - Regimentos das Câmaras Municipais ou Lei de $1^{\circ}$ de Outubro de 1828 1a. Ediçäo Eduardo \& Henrique Laemmert, Rio de Janeiro, 1868 2a. Ediçăo correta, anotada a aumentada por Antônio Joaquim de Macedo Soares, B. L. Garnier-Livreiro-Editor, Rio de Janeiro, 1885.

LEAL (Aurelino). - Histöria Constitucional do Brasil, Rio de Janeiro, 1915.

Do Ato Adicional à Maioridade (História Constitucional e Política), Rio de Janeiro, 1915. 
LEAL (Vitor Nunes). - Alguns problemas municipais em face da Constituição in Estudos sôbre a Constituiçāo Brasileira, diversos autores Fundação Getúlio Vargas, Rio de Janeiro, 1934.

LEITE (Serafim). - Cartas dos Primeiros Jesuitas do Brasil, vol. I., São Paulo, 1954.

LEME (Pedro Taques de Almeida Pais). - História da Capitania de São Vicente, Cia. Melhoramentos de São Paulo, São Paulo s/d.

LIMA JÚNIOR (Augusto de). - Cartas de D. Pedro I a D. João VI (coligidas, copiadas e anotadas por). Rio de Janeiro, 1941.

LISBOA (Baltazar da Silva). - Anais do Rio de Janeiro, Prefeitura do D. F.; 1941.

LISBOA (João Francisco). - Apontamentos para História do Maranhäo, in Obras, vol. II, Tipografia Matos Moreira \& Pinheiro, Lisboa, 1901.

LYRA (Tavares). - Organização Politica e Administrativa do Brasil (1500-1900) in Anais do Terceiro Congresso Nacional de História, vol. II., Rio de Janeiro, 1941.

LOBO (Eulália Lahmeyer). - Processo Administrativo Ibero-Americano, Edição Biblioteca do Exército, Rio de Janeiro, 1962.

LOPES (Fernão). - Crônica de D. Fernando introdução, seleção e notas de Torquato de Sousa Soares, Livraria Clássica Editôra, Lisboa, 1945.

LUfS (Washington). - Na Capitania de São Vicente, Livraria Martins Editôra, São Paulo, 1956.

MACHADO (Alcântara). - Vida e Morte do Bandeirante, Livraria Martins Editôra, São Paulo, 1948.

MAGALHÃES JUNIOR (R. de). - Três panfletários do Segundo Reinado, Editôra Nacional, São Paulo, 1956.

MAIA (Joāo de Azevedo Carneiro). - O Munictpio. 1a. ed. Tipografia de G. Leuzinger \& Filho, Rio de Janeiro 1883; 2a. ed., in O Pai do Municipalismo, com um estudo biográfico de autoria de Mário Maia Coutinho, Ed. Patrimônio, São Paulo, 1962.

MARTINS JÚNIOR (J. L.). - História do Direito Nacional, 2a. ediçāo - Cooperativa Editôra e de Cultura Intelectual Pernambuco, 1941.

MARTINS (Oliveira). - O Brasil e as Colônias Portuguêsas, 6a. ediçāo, Guimarães \& Cia. Editores, Lisboa, 1953.

MARTINS (Paulo Egídio). - Säo Paulo Antigo (1554-1910) $1^{\circ}$ volume, Livraria Francisco Alves, Rio de Janeiro, São Paulo e Belo Horizonte, 1911. 
MEDEIROS (Océlio). - O Govêrno Municipal no Brasil, Serviço Gráfico do IBGE, Rio de Janeiro, s/d.

MELLO (Diogo Lordello de). - A Moderna Administraçāo Municipal, Ed. da Fundação Getúlio Vargas, Rio de Janeiro, 1960.

MONCADA (L. Cabral de). - Estudos de História do Direito (3 volumes), Acta Univercitatis Conimbrigensis, Coimbra, 1948, 1949, 1950.

MONTEIRO (Tobias). - História do Império (Oo Primeiro Reinado) (2 volumes), F. Briguiet \& Cia. - Editores, Rio de Janeiro, 1939, 1946.

- A Elaboração da Independencia, F. Briguiet \& Cia. - Editores, Rio de Janeiro, 1927.

MORAIS (A. J. de Melo). - História do Brasil-Reino e Brasil-Império (de 1808 a 1871), Tomo I., Tipografia de Pinheiro \& Cia., Rio de Janeiro, 1871.

MORAIS (Prudente de). - Discurso em que defende a autonomia municipal, pronunciado na Asscmbléia Legislativa de São Paulo, na sessão de 3 de março de 1868. - Tipografia Ipiranga, São Paulo, 1868.

MOURÃo (João Martins de Carvalho). - 0 Municipio - sua importância no Brasil-Colonial e no Brasil-Reino. Situação em que ficaram pela Constituição de 1824 e pelo Ato Adicional, in Revista do Instituto Histórico e Geográfico Brasileiro, Tomo Especial, $1^{\circ}$ Congresso de História Nacional, 1916.

MAURo (Fréderic). - L'Expansion européenne (1600-1870), Nouvelle CLIO, Tome 27, Paris, 1967.

NoGUEIRA (J. C. de Ataliba). - Liçöes de Teoria Geral do Estado, (Aulas dadas na Faculdade de Direito da Universidade de São Paulo)., São Paulo, 1969.

— O Municipio e os Municipes. São Paulo, 1947.

NUNES (Castro). - História administrativa municipal, in "Revista do Instituto Histórico e Geográfico Brasileiro", Anais do $2^{\circ}$ Congresso de História Nacional, vol. II, Rio de Janeiro, 1931.

oMEgNa (Nelson). - A Cidade Colonial, Livraria José Olympio Editôra, Rio de Janeiro, 1961.

PAULA (Floriano Peixoto de). - Vilas de Minas Gerais no Periodo Colonial, in Revista Brasileira de Estudos Politicos, $\mathrm{n}^{\circ}$ 19, Universidade de Minas Gerais, Belo Horizonte, 1965.

PASSOS (Carlos de). - o problema da sucessāo de D. Joäo VI, in História de Portugal, vol. VII., Barcelos, 1935.

PAUPÉRIO (A. Machado). - O Municipio e seu regime jurídico no Brasil, Distribuidora Récord Editôra, Rio de Janeiro, 1959. 
PEREIRA (Ângelo). - D. João VI Principe e Rei. Emprêsa Nacional de Publicidade, Lisboa, MCMLVI.

PEREIRA (Horácio Gonçalves). - Recursos Municipais: Jurisprudência do Senado Paulista e dos Tribunais do País (3 volumes), São Paulo Editôra, São Paulo, 1925-1926.

PERES (Damião). - A Revolução de 1820 e seus antecedentes in História de Portugal, vol. VII., Barcelos, 1935.

PESSOA (Vicente Alves de Paula). - Codigo de Processo Criminal. Com todas as reformas até 1880, explicando, revogando e alterando muitos de suas disposições, organizado por Jacinto Ribeiro dos Santos - editor, Rio de Janeiro, 1889.

PITTA (S. da Rocha). - História da América Portuguesa - 3a, ediçāo, Livraria Progresso Editôra, Bahia, 1950.

POMBO (Rocha). - História do Brasil (5 volumes), W. M. Jackson Inc. Editores, São Paulo, 1935.

- História do Brasil - atualizada por Hélio Vianna, Cia. Melhoramentos de de São Paulo, São Paulo, 1967.

PRADO (Paulo). - Paulistica, Ariel, Rio de Janeiro, 1934.

RIBEIRO (João). - Fronteiras do Brasil -- 2a. edição, Livraria Progresso Editôra, Salvador, 1947 ( $?$ ).

- História do Brasil (curso superior), revista e completada por Joaquim Ribeiro - 17a. edição, Livraria Francisco Alves, Rio de Janeiro, São Paulo, Belo Horizonte, 1960.

RIBEIRO (Olympio Carr). - Instituições do Municipio de Säo Paulo in Arquivos de Direito Municipal, Prefeitura de São Paulo, $\mathrm{n}^{9}$ 1. Nota: neste número estão publicados apenas os três primeiros capítulos, os que mais interessam ao nosso estudo, pois vão de 1524 a 1898 - São Paulo, 1953.

ROCHA (Justiniano José da). - Ação; Reação; Transaçāo in Trés Panfletários do Segundo Reinado, de R. Magalhães Júnior, São Paulo, 1956.

ROMEIRO (João). - De D. Joäo d Independência, Rio de Janeiro, 1915.

RUY (Afonso). - História da Câmara Municipal da Cidade do Salvador, Câmara Municipal do Salvador, 1953.

SAMPAIO (Theodoro). - História da Fundaçāo da Cidade do Salvador, Tipografia Beneditina Ltda., Bahia, 1949.

SANT'ANNA (Nuto). - São Paulo Histórico (2 volumes), Coleção do Departamento de Cultura, São Paulo, 1937.

SILVA (Ignácio Accioli de Cerqueira e). - Memórias Históricas e Politicas da Provincia da Bahia, (5 volumes). Anotadas por Braz do Amaral, Imprensa Oficial do Estado da Bahia; 1919, 1925, 1931, 1933 e 1937. 
SILVEIRA (Uria: A. da). - Galeria Histórica da Revoluçāo Brasileira, Rio de Janeiro, 1890.

SMITH (T. Lynn). - Brasil - Povo e Instituį̧ōes, Trad. do Prof. José Arthur Rios, Ed. Bloch, Rio de Janeiro, 1967.

SODRE (Nelson Werncck). - Formação Histórica do Brasil - 4a. edição, Editôra Brasiliense, Rio de Janeiro, 1967.

SORIANO (S. J. da Luz). - Históric do cêrco do Pôrto (2 volumes), Pôrto, 1889-1890.

SOUSA (Otávio Tarquinio de). - História de dois Golpes de Estado, Livraria José Olympio Editôra, Rio de Janeiro, 1939.

- A Mentalidade da Constituinte ( 3 de maio a 12 de novembro de 1823), Oficina Gráfica A. P. Barthel, Rio de Janeiro, 1931.

- História dos Fundadores do Império do Brasil (10 vos.). Livraria José Olympio Editôra, Rio de Janeiro, 1957-1958.

- O Pensamento Vivo de José Bonifácio, Livraria Martins Editôra, São Paulo, 1945.

SOUSA (Galvão). - História do Direito Político Brasileiro, Edição Saraiva, São Paulo, 1962 .

SOUSA (José Paulino Soares de). - Vide Urugai.

SOUSA (Martim Afonso de). - Memórias de Editôra Obelisco, São Paulo, 1964.

SOUSA (Pêro Lopes de). - Diário da Navegação (2 volumes), Introdução e notas do Comte. Eugênio de Castro, Rio de Janeiro, 1940. Vide também, a edição da Ed. Obelisco, com Introdução de J. P. Leite Cordeiro, São Paulo, 1964.

SOUTHEY (Robert). - História do Brasil (6 volumes). - Trad. por Luís Joaquim de Oliveira Castro. Anotada por J. C. Fernandes Pinheiro, Brasil Bandecchi e Leonardo Arroyo, Editôra Obelisco, São Paulo, 1965.

TAMOYO (O.). - O (1823) jornal fundado para defender os Andradas quando êstes em 16 de julho de 1823, sofrendo forte oposiçāo, deixaram o Ministério, Edição Fac-similar da Editôra Zélio Valverde, Rio de Janeiro, 1914.

TAVARES (Luís Henrique Dias). - História da Bahia, Editôra Civilização Brasileira, Rio de Janeiro, São Paulo, Bahia, 1959.

TAUNAY (Afonso de E.). - João Ramalho e Santo André da Borda do Campo, Ediçāo da Prefeitura de Santo André, São Paulo, 1951.

História da Cidade de São Paulo. $1^{\circ}$ vol., 1949; $2^{\circ}$ vol., 1951; 3.० vol., com o título História Colonial da Cidade de Sāo Paulo (1801-1822), 1956; $4^{\circ}$ vol., com o título História da Cidade de São Paulo sob o Império 
(1822-1831). 5 vol., idem, (1831-1843), 1961. Divisão do Arquivo Histórico da Prefeitura Municipal. São Paulo.

- São Paulo nos Primeiros Anos (1554-1601), Imprensa de E. Arrault et Cie., Tours, 1920.

— São Paulo no século XVI, E. Arrault \& Cia., Tours, 1921.

TÓRRES (João Camilo de Oliveira). - O Conselho de Estado, Ediçōes G. R. D., Rio de Janeiro, 1965.

TRIPOLI (César). - História do Direito Brasileiro (2 volumes), Revista dos Tribunais, São Paulo, 1936-1947.

URUGUAI (Visconde do) (Paulino José Soares de Sousa). - Ensaio sôbre o Direito Administrativo (2 volumes), Tipografia Nacional, Rio de Janeiro, 1862 .

VARNHAGEN (Francisco Adolfo de). - História Geral do Brasil (6 volumes), Revisão e notas de Rodolfo Garcia, $1^{\circ}$ volume 6a. edição $5 a$. edição completa. Companhia Melhoramentos de São Paulo, 1956.

VASCONCELOS (Diogo). - Linhas gerais da administração colonial, in Revista do Instituto Histórico e Geográfico Brasileiro. Tomo Especial consagrado ao $1^{\circ}$ Congresso de História Nacional, Parte III.

VEIGA FILHO (J. P. da). - Estudo sôbre o voto e a eleiçăo, Tipografia a vapor de Jorge Seckper \& C., São Paulo, 1885.

VIANNA (Hélio). - História do Brasil (2 volumes), Companhia Melhoramentos de São Paulo, São Paulo, 1965.

VIANNA (Oliveira). - Instituiçōes Politicas Brasileiras (2 volumes), Livraria José Olympio Editôra, Rio de Janeiro, 1949.

XAvIER (Rafael). - Campanha Municipalista. Serviço Gráfico do Instituto Brasileiro de Geografia e Estatística, Rio de Janeiro, 1950.

- Evolução Histórica do Municipalismo no Brasil (conferência), Secretaria do Govêrno do Estado do Rio de Janeiro, 1949.

ZENHA (Edmundo). - O Municipio no Brasil (1532-1700), Instituto Progresso Editorial, São Paulo, 1948. 